\title{
The vasomotor symptoms and skin changes in natural menopause among Iranian women
}

\author{
Masoumeh Shohani ${ }^{1}$, Mahboobeh Rasouli ${ }^{2}$, Fatemeh Shohani ${ }^{3}$, Kourosh Sayehmiri ${ }^{*}$
}

1. Department of Nursing, Faculty of Allied Medical Sciences, Ilam University of Medical Sciences, Ilam, Iran

2. Blood Transfusion Research Center, High Institute for Research and Education in Transfusion Medicine, Tehran, Iran

3. Department of Psychology, Velayat First High School, Ilam, Iran

4. Department of Biostatistics, Faculty of Medicine, Ilam University of Medical Sciences, Ilam, Iran

*Corresponding author: Tel: +98 9183410782 Fax: +98 84332235721

Address: Department of Biostatistics, Faculty of Medicine, Ilam University of Medical Sciences, Ilam, Iran

E-mail: sayehmiri@razi.tums.ac.ir

Received; 2015/06/28 revised; 2015/08/21 accepted; 2015/08/26

\begin{abstract}
Introduction: Menopause is the most important event in middle-age. Women, in this period, face several changes. Vasomotor symptoms and skin changes are prevalent in the middle-age. This study, mainly, was performed identifying the vasomotor symptoms and skin changes in menopausal women.

Materials and methods: Study sample was consisted of 150 women who have visited the healthcare centers, experienced natural menopause as discontinuity of menstrual at least for 12-monthes. They have been selected randomly. Survey instruments were structured questionnaire, informational records, symptoms and signs checklist, centi-meter and balance and the data collecting method was through interview, observation, and examination. The data were analyzed using logistic regression.
\end{abstract}

Results: According to study results, skin warming and hotness (55.3\%), hands and legs nipping (63.3\%), hirsutism of pinion lip (27.3\%), reduction of armpit hair (38\%), acne (12\%), Skin extenuation and wrinkling $(51.3 \%)$ were reported. The most important point of the study is the significant relationship between amount of tea consumption and flushing severity $(\mathrm{P}=0.008, \mathrm{OR}=3.18)$. Also, there was a significant relation between education and menopause duration, sleep disorders and severity of flushing, menopause duration and skin collagen reduction $(\mathrm{P}<0.05)$.

Conclusion: Skin and vasomotor changes is prevalent in these women. Flushing severity influenced by tea consumption, such that drinking more tea will decrease the flushing, is the start point of more researches in this field.

Keywords: Signs and Symptoms, Skin, Menopausal women, Vasomotor system

\section{Introduction}

Menopause is one of the critical stage of women life (1), and is the most important event in middle-aged Women (40-65 years) (2). This stage is indicative of transiting from pregnancy and reaching infertility (3). According to world Health organization, menopause is discontinuity of menstrual for a period of 12 monthes because of Ovary follicles lacking activity (4). The women experience menopause at different ages and the common range is 50-52 years (5). Menopause is significance from social, cultural and personal point of view and is a special issue in hygienic 
issues in pregnancy field and women health $(6,7)$. Now days, many endocrines, mental and physiological changes have been attributed to menopause, which occurs due to estrogen Deficiency (8). An important physiological menopause symptom is vasomotor changes, which the flushing is the most prevalent.

Vasomotor Flushing symptoms are one of most prevalent and problem-making symptoms for women who had interred climacteric cycle. About $75-85 \%$ of women face that condition and is the most relevant symptom of pre-menopause $(9$, 10). $85 \%$ of women who experience flushing, carry the symptoms for more than a year and $25-50 \%$ of them will suffer Flushing for five years $(3,11)$. Flushing is a persecutor experience for approximately $40 \%$ of women (12). Often, most women experience Flushing before the last menstruation cycle (25\%) and, finally, Flushing symptoms will decrease in terms of repetition and severity, simultaneously with age increment; Unlike other consequences of menopause which gradually increase as time progress $(9,10)$. Flushing is a severe warmth psychic feeling in the upper body side which it vary from 30 s to 10 minutes and typically longs for four minutes (13). Most women state that Flushing will begin by feeling pressure in head and heartthrob and then they will have irritation and warmth in face, neck, chest, which will be followed, immediately, whole body perspiration, especially head, neck, upper chest and back (11). Other symptoms which are less prevalent are infirmity, tiredness, syncope and vertigo (3). Most frequently, Flushing will occur at night and may lead to patient's awaking. The sleep pattern will be distributed and it may lead to chronic tiredness, which probably can be identified through symptoms like irritability, weak concentration, memory disorder, depression and loss of interests $(9,12,14)$. It's possible that the seizures relapse for thirty times a day, but 5-10 times are more prevalent (15). Feeling insensitivity and nipping are the other vasomotor symptoms which had been seen in terms of insensitivity, creep, legs and hands nipping (16).

Skin changes are other symptom which will be seen in postmenopausal women. These changes include dryness, Thinning and wrinkling which appear due to elasticity reduction (17). Several evidences had proved that estrogen deficit play an important role causing these changes (15). It have been identified that collagen container and it's thickness decreases 1$2 \%$ annually, which in turn doesn't have any relation with age but to passed time of menopause (11).

Changes of hair setting will be seen in most women, after menopause. After menopause, Hirsutism and reduction of armpit and public area will reveal, all due to ovary inadequacy and also because of Gonadotropins increment. Body hairs may increase or decrease and sometimes may be seen mild baldness (11).

Most studies abut menopausal women experiences have been performed in developed and industrial countries, whereas a few studies had been performed by Asian countries. Considering economic, social, political conditions and organization of healthcare and women condition, the Asian countries are different from other countries. It is not surprising that reported findings of various studies are different (18-23). Also, look reported that Japanese women consider menopause an unimportant event while Flint reported that Indian women consider menopause as an award and sense of freedom (24). With respect to observed differences about menopause and its symptoms, we may state that symptomatology on menopause symptoms will indicate that these symptoms are connected to culture; mental, social, psychic conditions and emotional health are effective factors on menopause experience. In Iran, women constitute one-half of population. The agemean and life-hope as well as other countries are increasing, therefore we will 
have more menopausal women. Besides, Iran is a large vast country, with various ethnics of different cultures live in. So, prevalence and severity of menopause symptoms will vary along different regions. This study, mainly, was performed identifying the vasomotor symptoms and skin changes in menopausal women.

\section{Materials and method}

The present study was a cross-sectional study, conducted in order to assess the effective factors of vasomotor symptoms and skin changes in menopausal women. A stratified sample of $n=150$ menopausal women were recruited from the outpatient departments of 13 healthcare centers that were under the supervision of Ilam University of Medical Sciences, between August 2011 and December 2011. To determine the sample size in this study, the pilot study showed approximately $10 \%$ of postmenopausal women with no problem, therefore confidence level at $95 \%$, and margin of error at $5 \%$, the sample size was calculated to be 150 according to the following formula:

$$
n=\frac{Z^{2} 1-\frac{\alpha}{2} P(1-P)}{d^{2}}
$$

The number of subjects recruited from each center was determined by the population size that the particular center was designed treat. A cross-sectional survey was employed using a standardized questionnaire combined with medical record review and observation for collection of demographic characteristics, medical history and symptom scores for vasomotor symptoms and skin changes. Estimating amount of taken "Calcium" by the sample, we used pre-24 hours diet and we calculated "Calcium" in terms of $\mathrm{mg}$. Subject recruitment and interviews were conducted by two trained researcher. Subject eligibility criteria included participants between 40 and 65 years of age, who attended one of the 13 healthcare centers as an outpatient, were going through natural menopause (cessation of menstruation for a minimum of 12 months) and had no known mental or physiological illness. Inpatients and subjects admitted to hospital directly following the outpatient visit were excluded from the study. A research proposal was submitted to Tehran University of Medical Sciences .

The present study was approved by the Ethics Committee of Tehran University of Medical Sciences, Iran. Verbal consent was obtained by each participant for voluntary participation in the study. Data were stored on a password protected private computer at the researcher's office.

\section{Statistical analysis}

Results were expressed as mean \pm standard deviation or frequency as indicated. A Kolmogorov-Smirnov test was used to determine normality for continuous variables. Correlations between variables were analyzed using the Pearson correlation coefficient $®$ or Spearman rank correlation coefficient $\AA$, as appropriate. Univariate and multivariate logistic regression models were used to examine associations between menopause age and tea consumption, menopause duration. An alpha $<0.05$ was used to determine statistical significance .

\section{Results}

Demographic information and health records of samples demonstrated in Table1.

Results showed that majority (92.7\%) didn't take "Calcium" sufficiently and only (7.3\%) have taken "Ca" sufficiently. Taken Ca per 24-haour Mean was $603.9 \mathrm{mg}$. the average of sample ages was 54.9 years old and menopausal age average was 48.7 years. Signs and symptoms of vasomotor in the menopausal women, and their skin changes are presented in Tables 2 and 3, respectively. 
Table 1. Demographics characteristics of the studied samples.

There was a significant relation between degree of education and severity of flushing $(\mathrm{P}=0.031)$, menopausal duration and severity of flushing $(\mathrm{P}=0.000)$, menopause duration and skin collagen reduction $(\mathrm{P}=0.000)$, severity of flushing and sleep disorder $(\mathrm{P}=0.000)$. Whereas there wasn't any significant relation between severity of flushing with BMI and menopausal age, used Calcium and nipping and insensitivity $(\mathrm{P}>0.05)$. There was a significant relation between tea consumption amount and severity of flushing $(\mathrm{P}=0.008)$. Logistic regression coefficient, in this case, showed that tea consumption amount three and more glasses per day will decrease the probability of flushing by 3.18 times. Omitting confounding variable menopause age, by increasing menopause duration about a year, the probability of flushing will decrease by 1.3 times.

Log $\mathrm{p} / \mathrm{p}-1=-4.1+0.26$ tea consumption +1.15 menopause duration

The logistic model of relation between menopause duration and tea consumption and flushing in menopausal women. 
Table 2. The absolute and relative frequency of vasomotor signs and symptoms in the studied samples.

\begin{tabular}{lc}
\hline Symptom variable & Values ${ }^{\mathbf{a}}$ \\
\hline Hot flashes & $83(55.3)$ \\
Hot skin & $56(37.3)$ \\
Night sweat & $73(48.7)$ \\
Daily sweat & $56(37.3)$ \\
Hands ,face and neck redness & $65(43.4)$ \\
Headache & $57(38)$ \\
Weakness & $46(30.7)$ \\
Tiredness & $39(26)$ \\
Nausea & $8(5.3)$ \\
Vomiting & $72(48)$ \\
Sleeping late & $38(25.3)$ \\
Early waking & $72(48)$ \\
Waking during the night & \\
Sleep disorders & $49(32.7)$ \\
Needles and pins in hands and feet & $68(45.3)$ \\
insensibility & $90(60)$ \\
hands and legs nipping & $95(63.3)$ \\
\hline Numbness and insensibility in the extremities
\end{tabular}

${ }^{a}$ Values are presented as Number(\%).

Table 3. The absolute and relative frequency of skin signs changes in the studied samples.

\begin{tabular}{lc}
\hline Symptom variable & Values $^{\text {a }}$ \\
\hline Hirsutism & $41(27.3)$ \\
in the upper lip & $24(36)$ \\
in the chin & $8(5.3)$ \\
in the cheeks & \\
Reduction of hair & $57(38)$ \\
in Armpit & $56(37.3)$ \\
in above the pubic & $18(12)$ \\
Acne & \\
Reduction of collagen & $77(51.3)$ \\
Thinning and wrinkling & $71(47.3)$ \\
\hline
\end{tabular}

${ }^{\mathrm{a}}$ Values are presented as Number (\%).

In this model, the dependable variable, flushing probability, and tea consumption and menopause duration are the independent variables. In this model, knowing amount of daily drinking tea and menopause duration we will able to estimate flushing probability. The model sensitivity is $83.1 \%$ and its characteristic (property) is about $65.7 \%$.

For analyzing the relation between tea drinking and probability of flushing, amount of tea consumption in terms of glass has been defined as the independent (anticipatory) variable and number of flushing symptoms as the dependents (illuminated) variable. The distribution chart of data and line equation of linear regression has been shown in Figure 1. The chart shows that, increment of tea consumption will reduce flushing symptoms $(\mathrm{p}=0.000, \mathrm{r}=0.34)$; its equation is as follow:

$\mathrm{y}=7.57-1.052$ tea consumption 


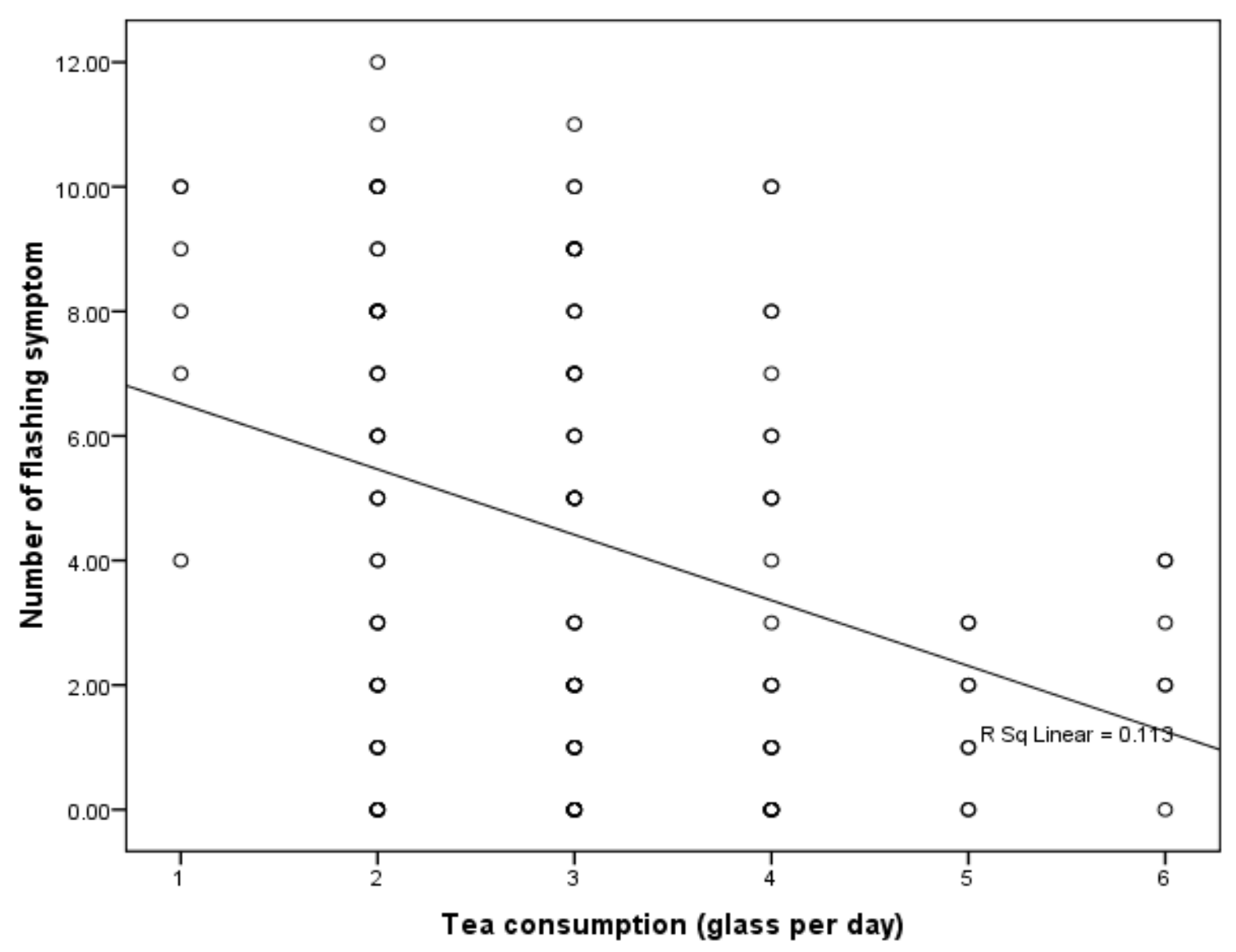

Figure 1. Relationship between tea consumption and probability of flashing.

This equation shows that increment of tea consumption amount by one glass per day will normally decrease one of the flushing symptoms .

Study results showed that there is a significant relation between menopause duration and severity of skin collagen reduction $(\mathrm{P}=0.000)$. In this equation, the logistic regression model showed that menopause duration increment by a year, the reduction of skin collagen will increase by 1.23 times. The probability of reduction of skin collagen is $(\mathrm{P}=0.000)$ in this model. $\log \mathrm{p} / 1-\mathrm{p}=-1.38+0.23$ menopause duration $(\mathrm{OR}=1.23, \mathrm{P}=0.000)$

\section{Discussion}

Estrogen hormone deficiency in women is accompanied by several physiological, mental and endocrine changes. This study analyzes vasomotor and skin changes, in terms of symptoms and signs. One of the most significant issues in this study, was considering women who had natural menopause (without System genital operation which leads to menopause), had passed 12-monthes from menopause and didn't have mental or physiological diseases in past year. Analyzing symptoms and signs was performed in terms of available literature and researches and the relation between these changes and personal and health records. Average of menopause age of the sample population was 48.7 years which is consistent with other researches which have been performed in Iran $(23,25,27)$. But, is lower comparing to average of menopause age in other Asian, Caucasian and western developed countries $(24,26,28)$. But, actually the difference of natural menopause age other than environmental, economic, social and genetically factors, is correlating with factors like differences of 
menopause definition, sample population and study method.

In this study, analyzing health behaviors showed that the samples didn't take calcium sufficiently $(603.9 \mathrm{mg}$ per 24 hours). Whereas the recommended calcium taking amount was $1500 \mathrm{mg}$ for people under 65years old without intake estrogen (29). Although living place of samples was sunny, they didn't stand against sun and most of them didn't exercise. Results of study are consistent with other studies $(23,30)$. We believe that, under-level education; lack of conscious, lack of training at medical healthcare centers and lack of providing programmed services to menopausal women may be due to disregarding healthy desirable behaviors. The researcher believes that dis-taking calcium in the sample may be due to improper feeding (drinking milk with foods that keep back calcium and lack knowledge about proper feeding) and lack of knowledge about milk drinking for prevention of bone problems.

The results showed that experiences of sample women of study are consistent with other studies which have been performed in other American, Asian and so on countries; although there was some difference in terms of severity and prevalence.

Flushing is the most prevalence symptom of vasomotor which was similar to performed studies in Iran (31), Asia (32, 33), Australia (19), Turkey (18), and Spain (34). Vasomotor symptom's prevalence was significantly fewer in some studies including southeastern-Asian Countries (35), Singapore (26), Nigeria (22) and Japanese-American (20).

This difference may be due to biological differences of different races, life style, cultural and social issues and Asian diet in which contain huge amounts of Phytoestrogen $(26,34,36)$. In this study, $51.3 \%$ of women have reported increment of skin wrinkling that increases with increment of menopause duration. Conboy et al, also, reported changes in skin collagen and tune surface (63\%) (32) and Nigerian women reported skin dry $30 \%$ (22). These changes are important, in terms of elegance, and women consider them as begging of menopause (11).many evidences showed that these changes du to estrogen deficiency $(15,37)$.

In our study, there was a significant relation between some demographic and health variables and prevalence of menopause symptoms .

There was a significant relation between degree of education and flushing severity, thus, higher degree of education was corresponded to reduction of flushing. This finding is in contrast to Pakravesh findings. She had reported that there is not any significant relation between degree of education and vasomotor symptoms (23). It may be due to this fact that higher education will bring more information for women and they will gain more medical services.

The relationship between BMI and Flushing was not significant, where the clinical results are significant, show that fat women face less flushing. The finding of longitudinal studies is showed a significant direct relation between BMI increment and moderate to severe flushing $(10,38)$.

About this issue, Decherney and Nathan state that: prevalence of flushing is lesser in fat women; which is probably due to more estrogen production and reduction of gamaglobin, which adjoins the sexual hormones in these women (11).

There is a significant relation between menopause duration and severity of flushing, thus, increment of menopause duration will decrease the severity of flushing. This result is consistent with other studies finding which the prevalence of flushing in less than 5years menopause women is $(56.2 \%)$ and was \%45 for women more than 5 years duration (21, 31).

Ryan, confirming this finding, state that: flushing symptoms will decrease in terms of growing older; unlike other 
consequences of menopause which increase by time (9).

The most important finding of this study is the significant relation between amounts of tea consumption per 24-houre and severity of flushing $(\mathrm{o}=0.008, \mathrm{OR}=3.18)$. Thus, women who were drinking more than 3 glasses tea per 24hours will decrease the probability of flushing by 3.18 times .also increment of tea consumption amount by one glass per day will normally decrease one of the flushing symptoms $(\mathrm{p}=0.000$, $\mathrm{r}=0.34)$.

According to previous studies, Caffeine consumption and alcohol drinking will intensify flushing (13). But considering tea drinking effect on flushing nothing has been mentioned. With respect to the study results, we can say that tea will bring about flushing reduction .

Flushing severity has caused sleep disorder; thus flushing severity increment will intensify sleep disorder. There was a significant relation between flushing and sleep disorder $(3,10)$; such that menopause women $(56 \%)$ has mentioned flushing as the primary reason of sleep disorders (13).

Taken calcium amount per 24-hours didn't affect nipping and insensitivity $(\mathrm{p}=0.53)$. It may be due to this condition that minority of people had taken calcium per 24-hours sufficiently comparing to who hadn't taken calcium sufficiently .

There was a significant relation between menopause duration and skin collagen reduction $(\mathrm{OR}=1.23, \mathrm{p}=0.000)$; such that menopause duration increment by a year, the reduction of skin collagen will increase

\section{References}

1. Abrernethy K. The menopause and HRT. 2rd ed. Edinbiurg: Bailliere Tindall; 2002. P.159.

2. Liewellyin-Jones D. Fundamental of obstetrics and gynecology. 9rd ed. London: Mosby Co: 2010. P.322. by 1.23 times. Confirming this condition, Decherney and Nathan stated that collagen content and skin thickness in menopausal women will decrease 1-2\% annually and elasticity reduction doesn't have any relation with age but rather, is in relation with menopause duration (11).other studies showed that there is a strong relation between skin changes and estrogen deficiency in menopausal women (39-42).

\section{Conclusion}

The study results showed that skin changes and vasomotor symptoms were seen at different degrees in menopausal women; which in some cases are similar to results of studies which have been performed in Iran and other countries; although there is some dissimilarity. These similarities and dissimilarities may be affected by social, cultural, environmental factors, life style and so on. The most important result of this study is that tea consumption results in reduction of flushing in menopause women, which we didn't find similar results. This point can be a good begging for performing more studies in this field.

\section{Acknowledgments}

We would like to thank and acknowledge medical and healthcare centers of Ilam city's personnel for hearty cooperation and respectful professors of the Nursing and midwifery college of the Tehran University of Medical Sciences for their guidance.
3. Scott J. Danforth's obstetrics \& gynecology. 10rd ed. Philadelphia: Lippincott. W \& W Co; 2008. P.333.

4. Bobak I. Maternity and women's health care. 10rd ed. St-Louis: Mosby Co; 2011. P.577.

5. Speroff L, Fritz MA. Clinical gynecology endocrinology and 
infertility. 8rd ed. New York: Lippincott, W \& W Co; 2010. P.433.

6. Eskin B. The menopause: the comprehensive management. 4rd ed. NewYourk: The Parthenon Publishing Group; 1999. P.559-563.

7. Stanhope $M$ and Lancaster J. Community \& public health nursing. 6rd ed. St-Louis: Mosby Co; 2008.P.605.

8. Sakala E. High-yield obstetrics and gynecology. 2rd ed. New York: Lippin Cott, W \& W co; 2005.P.270-273.

9. Ryan, K. Kistner's gynecology and women health. 7rd ed. St-Louis: Mosby Co; 2005.P.430-432.

10. Ford K, Sowers MF, Crutchfield M. A longitudinal study of the predictors of prevalence and severity of symptoms commonly associated with menopause. J Menopause. 2005; 12 (3): 308-17.

11. Decherney AM, Nathan L. Current obstetric \& gynecologic diagnosis and treatment. 11rd ed. NewYourk: Mc Graw Luill Co; 2012. P.670-683.

12. Hacker NF, Moore JG. Essentials of obstetrics and gynecology. 3rd ed. Philladelphia: Sannders Co; 2004. P. 499-605.

13. Brown K. Management guide lines for women's Health Nurse Practice. Philadelphia: F.A. Davis; 2000. P. 501513.

14. Zervas LM, Lambrinoudaki I, Spyropoulou A. Additive effect of depressed mood and vasomotor symptoms on postmenopausal insomnia. J Menopause. 2009;16 (4): 837-42.

15. Berek J. Novak's gynecology. 15rd ed. Philadelphia: Lippincott. W \& W co; 2014. P. 1340-1351.

16. Willocks J and Phillips K. Obstetrics and gynecology. 5rd ed. London: Churchill Living Stone; 1997. P.329330.

17. Gangar EA. Gynecological nursing, a practical guid. Philladelphia: Churcill Living Stone; 2001. P.189.
18. Ho S. The prevalence of osteoporosis in the Hongkong Chinese female population. J Maturitase. 1999;32: 171-8.

19. Dennerstein L. Are changes in sexual functioning during midlife due to aging or menopause? J Fertility \& Sterility. 2001; 76(3): 456-60.

20. Sievert LL, Morrison L, Brown DE. Vasomotor symptoms among Japanese-American and EuropeanAmerican women living in Hilo, Hawaii. J Menopause. 2007;14(2): 261-9.

21. Berecki-Gisolf J, Begum N, Dobson AJ. Symptoms reported by women in midlife: menopausal transition or aging? J Menopause. 2009; 16(5): 1021-9.

22. Ogbera A, Fasanmade O, Kalra S. Menopausal symptoms and the metabolic syndrome in Nigerian women with type 2 diabetes mellitus. J Climacteric. 2011; 14(1):75-82.

23. Pakravesh F. The knowledge menopausal women about menopause and its relationship with vasomotor signs and depression prevalence .MSc Midwifery thesis, Tehran University of medical sciences. 1996. P: 257-68.

24. Punyahotra, S. Menopausal experiences of Thai women: symptom and their correlates. J Maturitas. 1997; 26: 1-7.

25. Abedi S. The relationship between BMI and menopause age in menopausal women in Tehran. MSc Midwifery thesis, Tehran University of medical sciences. 1999. P: 221-30.

26. Chim M. The prevalence of menopausal symptom in community in Singapore". J Maturitas. 2002; 41: 275-82.

27. Fallahzadeh H. Age at natural menopause in Yazd, Islamic Republic of Iran. J Menopause. 2007; 14(5): 900-4.

28. Dratva J, Gomez Real F, Schindler Ch. Is age at menopause increasing across Europe? Results on age at menopause 
and determinants from two populationbased studies. J Menopause. 2009; 16(2):385-94.

29. Blak JM. Medical-Surgical Nursing, Clincal Mangment for Positive Outcomes. 8rd ed. Philladelphia: Saunders Co; 2008. P. 351-363.

30. Abdoli S. Evaluation of the amount of preventive factors function from osteoporosis in menopausal women referring to the health care centers of Tehran University of medical sciences in 2002. MSc Nursing thesis, Tehran University of medical sciences. 2003. P: 221-230.

31. Yousof Zadeh S and Jaafar Zadeh S. The prevalence of menopausal symptoms and age of menopause in Sabzevar women. J Asrar. 2000; 6(2):58-67.

32. Conboy L. Women at mid-life: symtoms, attitudes, and choices, an internet based survey. $\mathbf{J}$ Maturias. 2001; 38: 129-36.

33. Obermeyer C. Symptom reporting around the menopause in Beirut, Lebanon. J Maturitas. 1999; 33: 24958.

34. Schnatz P, Banever A, Greene J. Pilot study of menopause symptoms in a clinic population. J Menopause. 2005; 12(5): 623-9.
35. Boulet MJ .climacteric and menopause in seven South- East Asian countries. J maturitas. 1994; 19(3):157-76.

36. Rizk DE. The age and symptomatology of natural menopause among United Arab Emirates women. J Maturitas. 1998; 29:197-202.

37. Cary J Ch \& Rayburn WF. Obstetrics and Gynecology. 4rd ed. St. Louis: Lippin Cott. W \& W; 2002.P.571-579.

38. Pasquali R, Casimirri F, Labate AM, Tortelli O, Pascal G, Anconetani $\mathrm{B}$, et al. Body weight, fat distribution and the menopausal status in women. The VMH Collaborative GroupInt. J Obes Relat Metab Disord. 1994; 18(9):614-21.

39. Bensaleh H, Belgnaoui FZ, Douira L. Skin and menopause. Ann Endocrinol. 2006; 67(6):575-80.

40. Patriarca MT, Goldman KZ, Dos Santos JM. Effects of topical estradiol on the facial skin collagen of postmenopausal women under oral hormone therapy: a pilot study. Eur J Obstet Gynecol Reprod Biol. 2007; 130(2):202-5.

41. Calleja-Agius J, Muscat-Baron Y, Brincat MP. Skin ageing. J Menopause. 2007; 13(2):60-4.

42. Brincat MP. Oestrogens and the skin. J Cosmet Dermatol. 2004; 3(1):41-9. 